\title{
Modified Vaccinia Virus Ankara Vaccine Expressing p53
}

National Cancer Institute

\section{Source}

National Cancer Institute. Modified Vaccinia Virus Ankara Vaccine Expressing p53. NCI

Thesaurus. Code C116868.

A cancer vaccine comprised of a recombinant modified vaccinia Ankara (MVA) viral vector encoding the wild-type form of the tumor protein p53 (wt p53), with potential immunostimulating and antineoplastic activities. Upon subcutaneous vaccination with MVA vaccine expressing p53, the expressed p53 may stimulate the host immune system to mount a p53-specific cytotoxic T-lymphocyte $(C T L)$ response against tumor cells expressing p53, resulting in tumor cell lysis. The MVA viral vector, derived from the replication-competent strain Ankara, is a highly attentuated, replication-defective vaccinia strain and is incapable of virion assembly. The p53 gene, a tumor suppressor gene, is mutated in many cancer cell types. 